\title{
POLÍTICAS DE EDUCAÇÃO SUPERIOR NO BRASIL NA PRIMEIRA DÉCADA DO SÉCULO XXI: ALGUNS CENÁRIOS E LEITURAS
}

\author{
Paulo Gomes Lima*
}

\begin{abstract}
* Doutor em Educação Escolar pela UNESP. Professor Adjunto - Universidade Federal de São Carlos Campus Sorocaba. Sorocaba, SP, Brasil. E-mail: paulolima@ufscar.br

Resumo: O processo de expansão e democratização do acesso à educação superior no Brasil ocupou em larga escala a agenda de governo de Luís Inácio Lula da Silva, entre planos e programas. O PDE [Plano de Desenvolvimento da Educação] reunindo metas para a educação básica (Decreto Nº 6094 de 24/04/2007), as Diretrizes para o processo de integração de instituições federais de educação tecnológica para fins de constituição dos IFETS (Decreto $N^{\circ} 6095$ de 24/04/2007) e o Decreto $\mathrm{N}^{\circ}$ 6096 de 24/04/2007 que instituiu o programa de apoio a planos de Reestruturação e Expansão das Universidades Federais são exemplos significativos dessa ênfase, objeto de discussão nesse artigo. Esse trabalho discute até que ponto tais ações contribuíram efetivamente para finalidade a que estavam destinadas, considerando as contradições estruturais do sistema capitalista, além do que se elenca algumas pontuações reflexivas quanto à possibilidade de se construir uma universidade no Brasil não excludente e promotora da dimensão de democracia e universalização.
\end{abstract}

Palavras-chave: Universidade brasileira. Democratização. Universalização.

\section{HIGHER EDUCATION POLICIES IN BRAZIL DURING FIRST DECADE OF THE 21ST CENTURY: SOME SCENARIOS AND READINGS}

Abstract: The process of expansion and democratization of access to higher education in Brazil has been the main concern of Luís Inácio Lula da Silva's government agenda, its plans and programs. The Education Development Plan (PDE), gathering goals for basic education (Decree No. 6094 of April 24, 2007), the Directives for the process of integration of federal institutions of technological education for the constitution of the IFETS (Decree No. 6095 of April 24, 2007) and Decree No. 6096 of April 24, 2007, which instituted the plan for Restructuring and Expanding Federal Universities, knows as REUNI, are significant examples of this emphasis - objects of discussion of this article, whose purpose it is to point out the extent to which such actions effectively contributed to the achievement of the established goals, considering the structural contradictions of the capitalist system. The paper also presents some punctual considerations about the possibility of constructing a university in Brazil which does not exclude and which does promote democracy and universalization.

Key words: Brazilian university. Democratization. Universalization.

\section{INTRODUÇÃO}

Como observado em apontamentos anteriores (LIMA, 2009, 2012), a década de 1990 forneceu elementos contextuais imprescindíveis à compreensão das discussões sobre as condições de acesso, permanência, democratização e universalização à educação superior pública no Brasil. 
Todo esse cenário foi condicionado por leituras da nova organização do trabalho em nível mundial, via organismos multilaterais e influenciaria fortemente as políticas públicas no Brasil, em especial as educacionais [Conferência Mundial de Educação para todos (1990), Encontro de Nova Delhi (1993) e Reunião de Kingston na Jamaica (1996)] e àquelas voltadas para o ensino superior propriamente [Conferencia Mundial sobre Ensino Superior - 1998, 2009/ Declaração de Bolonha, 1999].

O cerne da discussão nesses eventos, principalmente da Conferência Mundial sobre Ensino Superior realizada no período de 5 a 9 de outubro de 1998 em Paris era a denunciada "inadequabilidade da estrutura e funcionamento" da universidade frente ao mundo globalizado e em processo de reestruturação econômica; daí a proposição da nova missão e função da universidade para o século XXI: 1) A universidade tem a missão de educar, formar e realizar pesquisas; 2) Função ética, autonomia, responsabilidade e prospectiva.

No âmbito da criação de uma nova visão de ensino superior, a CMES, destacava: 3) Igualdade de acesso; 4) Fortalecimento da participação e promoção do acesso das mulheres; 5) Promoção do saber mediante a pesquisa nos âmbitos da ciência, da arte e das humanidades e da difusão de seus resultados; 6) Orientação a longo prazo fundada nas atribuições; 7) Reforçar a cooperação com o mundo do trabalho e a análise e previsão das necessidades da sociedade; 8) A diversificação como meio de reforçar a igualdade de oportunidades; 9) Métodos educativos inovadores: pensamento crítico e criatividade; 10) Os professores e estudantes são os principais protagonistas da educação superior.

Sobre a passagem da visão para a ação foram destacados os seguintes pontos: 11) Avaliação da qualidade; 12) O potencial e os desafios da tecnologia; 13) Reforçar a gestão e o financiamento da educação superior; 14) O financiamento da educação superior como serviço público; 15) Ter em comum os conhecimentos teóricos e práticos entre os países e continentes; 16) Do "êxodo de competências" ao seu retorno (Programas de cooperação internacional e 17) as associações a alianças (DECLARACIÓN MUNDIAL SOBRE LA EDUCACIÓN SUPERIOR, 1998).

A leitura desse quadro solicitava aos países signatários esforços para a erradicação da pobreza, da elevação de maior acervo cultural dos países periféricos, das reorientações das políticas educacionais com suporte técnico de organizações multilaterais e da dimensão da justiça social, da universalização e democratização do acesso ao ensino superior, por meio de políticas de inclusão social, dentre outras. 
No período que antecedeu o término da segunda gestão do governo de Fernando Henrique Cardoso, o PPA (Plano Plurianual 2000- 2003) foi aprovado pelo Congresso, o qual refletia em sua quase totalidade os pontos derivados das discussões da reestruturação produtiva mundial. É oportuno o destaque dos eixos mobilizadores do Plano Plurianual que deveriam orientar os programas estratégicos em cada ministério e para cada setor do governo:

- Consolidar a estabilidade econômica com crescimento sustentado.

- Promover o desenvolvimento sustentável voltado para a geração de empregos e oportunidades de renda.

- Combater a pobreza e promover a cidadania e a inclusão social.

- Consolidar a democracia e a defesa dos direitos humanos.

- Reduzir as Desigualdades Inter-Regionais.

- Promover os Direitos de Minorias Vítimas de Preconceito e Discriminação.

Orientados por estes eixos, foram traçados 28 objetivos para serem alcançados pelo PPA até o final de sua vigência (2003) dos quais destacamos três (03): 1) Criar um ambiente macroeconômico favorável ao crescimento sustentável; 2) Elevar o nível educacional da população e ampliar a capacitação profissional e 3) Ofertar escola de qualidade para todos. Esses eixos não foram implementados no governo de Fernando Henrique Cardoso, mas seria parte dos encaminhamentos do governo posterior (Lula da Silva).

No governo de Luis Inácio Lula da Silva, tais pontuações não passariam à margem, mesmo porque, desde o final da década de 1990, muitas discussões convocadas por organismos multilaterais delineavam a "missão e função da educação superior" para o século XXI, seguidas de outras manifestações que à luz dessa primeira apontavam modificações estruturais e de funcionamento tanto para o caso dos países latino-americanos conforme rezavam os acordos internacionais, como também para o caso da comunidade europeia, via Processo de Bolonha de 1999.

Esse pano de fundo é necessário para se entender as pontuações sobre os condicionantes e abrangência das políticas educacionais e ações governamentais na gestão de Luis Inácio Lula da Silva quanto a expansão, a democratização do acesso e encaminhamentos da educação superior no Brasil e que certamente delimitou parte da estruturação do PDE [Plano de Desenvolvimento da Educação] por meio do Decreto N 6094 de 24/04/2007 "Todos pela Educação", as Diretrizes para o processo de integração de instituições federais de edu- 
cação tecnológica para fins de constituição dos IFETS [Decreto $\mathrm{N}^{\circ} 6095$ de 24/04/2007] e do Decreto $N^{\circ} 6096$ de 24/04/2007 que instituiu o programa de apoio a planos de Reestruturação e Expansão das Universidades Federais. À luz dessas três iniciativas governamentais, discutir-se-á o alcance da expansão e democratização do acesso à educação superior para a realidade brasileira, considerando as contradições estruturais entre proposições e necessidades reais da sociedade.

\section{O PLANO DE DESENVOLVIMENTO DA EDUCAÇÃO (PDE) E A DEMOCRATIZAÇÃO DO ACESSO À EDUCAÇÃO NO BRASIL}

O Programa de Aceleração do Crescimento [PAC] apresentado pelo governo Lula à sociedade brasileira, passou a vigorar a partir de 28 de janeiro de 2007. Caracterizado como um conjunto de políticas voltado à aceleração do crescimento econômico do Brasil, o principal ponto do programa estaria direcionado para o investimento em infraestrutura, dentre as quais: saneamento, habitação, transporte, energia, recursos hídricos. Entretanto, em cumprimento à agenda governamental já prevista inclusive pelo governo anterior, havia que se complementar o mesmo com oportunizações e geração de empregos, o combate à pobreza, a promoção da cidadania e inclusão social, o que passaria necessariamente dentre outras políticas, pela educação e o Plano de Desenvolvimento da Educação [PDE] que teve como abertura o Plano de Metas “Compromisso Todos pela Educação" [Decreto N. 6094/2007] e que viria a se caracterizar como um primeiro mapeamento de ações a serem desenvolvidas nesse intuito.

O PDE foi caracterizado pelo próprio presidente Lula como "Uma revolução na educação brasileira" e que, a seu ver, deveria responder a lacunas históricas até então não contempladas de forma parcial ou em sua totalidade. Esse primeiro delineamento previa a articulação da sociedade civil e os entes federados para, estrategicamente, promover a oferta de educação para todos e de qualidade. Isso se faria mediante parcerias e controle dos índices registrados quanto ao aproveitamento discente (IDEB) e a verificação sazonal por avaliações externas como, por exemplo, SAEB, Prova Brasil, ENEM.

Quanto à educação superior, as palavras expansão e democratização seriam os norteadores no contexto das razões do PDE, considerando os seguintes princípios:

i) expansão da oferta de vagas, dado ser inaceitável que somente $11 \%$ de jovens, entre 18 e 24 anos, tivessem acesso a esse nível educacional, 
ii) garantia de qualidade, pois não bastaria ampliar o número de vagas à universidade, seria preciso fazê-lo com qualidade,

iii) promoção de inclusão social pela educação, minorando o histórico de desperdício de talentos, considerando que significativo contingente de jovens competentes e criativos têm sido sistematicamente excluídos por um filtro de natureza econômica,

iv) ordenação territorial, permitindo que o ensino de qualidade fosse acessível às regiões mais remotas do País, e

v) desenvolvimento econômico e social, fazendo da educação superior, enquanto formadora de recursos humanos altamente qualificados ou como peça imprescindível na produção científico-tecnológica, elemento-chave da integração e da formação da Nação. (BRASIL, 2012).

Sem dúvida alguma o estabelecimento de políticas para o desenvolvimento da democratização na educação superior no Brasil é urgente e decisivo para romper com a educação de elite historicamente enraizada. No entanto, o PDE, como uma interface das políticas educacionais, segundo Saviani (2009), pode ser caracterizado muito mais como um "programa de metas" do que um plano propriamente dito, dadas as tentativas pontualizadas para se alcançar algumas metas em determinado tempo (2017), visando a duplicação de vagas no ensino superior, ficando aquém da proposta do PNE (2001-2010) que, pelo menos previa um número total de vagas para $30 \%$ dos jovens entre 18 e 24 anos (e mesmo assim não alcançou o alvo para a década), Portanto, um alvo tangível. Para atingir as metas do PDE, três instrumentos foram considerados como determinantes:

a) Reestruturação e expansão das universidades: REUNI [Programa de Apoio a Planos de Reestruturação e Expansão das Universidades Federais] e PNAES [Plano Nacional de Assistência Estudantil];

b) Democratização do acesso: PROUNI [Programa Universidade para Todos], reformulação do FIES [Fundo de Financiamento ao Estudante do Ensino Superior];

c) Avaliação e regulação: SINAES [Sistema Nacional de Avaliação da Educação Superior] via ENADE (Exame Nacional do Desempenho dos Estudantes]. 
Embora o desenvolvimento do Plano Nacional de Educação (2001-2010) estivesse em desenvolvimento, como se explicaria a elaboração do PDE e seu estabelecimento de ações via decretos governamentais, considerando a observação de Saviani, quanto a ser este antes um "programa de metas" do que um plano de educação? Por que ocorreu a proposição naquele momento histórico e não quando da conclusão do PNE que estava em curso, quando aí sim, se justificaria a construção do próximo PNE (2011-2020)?

Como perspectiva de resposta, entende-se que o governo, por meio de um acompanhamento prévio sobre a realidade educacional, considerando o próprio PNE, a plataforma de propostas do governo Lula e o estabelecimento de algumas diretrizes para o PNE posterior (2011-2020), se antecipou em responder a algumas solicitações sociais, dentre elas a universalização e democratização da educação básica e superior, como a "revolução na educação do governo da situação", o que prepararia a continuidade do poder pós-Lula.

Por outro lado, ao se observar a pontuação do PNE (2001-2010) e a necessidade de submissão a acompanhamentos periódicos sobre o alcance das finalidades a que se prestava, conclui-se que na verdade houve demora numa devolutiva para o enfrentamento dos resultados [parciais] que estavam latentes e que passariam a ser contemplados via PDE e na instituição dos instrumentos de ação que fariam frente às solicitações identificadas como frágeis pela plataforma de governo.

Em relação ao tempo histórico da proposição ${ }^{1}$ do $\mathrm{PDE}$, que compunha o mesmo período do PAC e era parte deste último, a sua implementação naquele período se mostrava estratégica para justificar algumas modificações e encaminhamentos instrumentais em curto prazo, com maior visibilidade política das ações do governo, mostrando a capacidade de resposta aos delineamentos insuficientes anteriormente propostos do governo anterior (Fernando Henrique Cardoso), o que realmente aconteceria quando ao término dos dez anos de vigência do PNE (2001-2010), ou seja, houve ampla divulgação do que não se alcançou e o que o governo estaria desdobrando uma ampliação e alcance da democratização do acesso em todos os níveis.

Veja-se que os dados disponíveis no INEP apontariam que cerca de 680 mil crianças entre 7 e 14 anos ainda estavam fora da escola nas regiões norte e nordeste, o que significava um percentual de $2,4 \%$ da população brasileira.

1 Saviani (2009) adverte que o PNE (2001-2010) previa em artigo $3^{\circ}$ avaliações periódicas do alcance de suas ações, assim no quarto ano de vigência que se situaria em 2004 isto deveria acontecer, a fim de se corrigirem as deficiências e distorções, mas de fato o dispositivo legal não foi observado. Somente quando estava a menos de quatro anos para ser finalizado o PNE, foi anunciado o PDE. Ora, daí a considerar a estratégia de tal proposição naquele espaço tempo. 
A EJA tinha alcançado apenas 30\% de cobertura de alcance dos 29 milhões identificados, isto é, apenas 10,9 milhões. Reduziu-se o abandono da escola no ensino fundamental, mas aumentou-se a repetência (de 11 para 12,1\%). O analfabetismo ainda não conseguira ser erradicado compreendendo mais de 16 milhões de pessoas. Na pré-escola ainda estariam faltando $2,4 \%$ para se atingir o parâmetro de $80 \%$ das crianças com essa idade e ainda sobre as crianças em idade de creche apenas $17,1 \%$ da meta de $50 \%$ para esse âmbito havia sido alcançado.

Num outro quadro, a educação profissional e tecnológica representou até 2010, um crescimento considerável em nível de expansão de unidades por todo país, mas ainda haveria que se pensar nas desigualdades ou distribuição regional na oferta de vagas, pois em números o universo de alunos matriculados nessa modalidade totalizavam menos de $1 \%$, se considerada a população total do Brasil, isto é, não havia vagas para grande parte de interessados.

E a educação superior, por sua vez, não atingira o montante dos $30 \%$ estabelecidos dos jovens entre 18 e 24 anos de idade (somente se alcançara o percentual de $12,1 \%$ ), além do que $74,1 \%$ das matrículas $(68 \%$ no período noturno) estavam circunscritas às instituições privadas e somente $25,9 \%$ no setor público e desses $36 \%$ no período noturno.

Esta prévia também estaria presente nos indicadores do PNE (2001-2010). A construção do PDE (que reuniu pela primeira vez o empresariado, no entanto, que não definiu esforço de inversões financeiras efetivas para a educação brasileira) se revelaria como a demonstração da capacidade de enfrentamento a quadros adversos do contexto educacional do novo governo, daí a grande preocupação na reunião de "alguns" setores sociais na elaboração do PDE (2007), o que não poderia ser caracterizado por uma dimensão ampla de discussão com toda a sociedade e representantes da academia, pelo contrário, a sua dimensão de democracia havia sido reduzida.

Ramos (2007) observa que na elaboração e processo de implementação do PDE não houve uma participação direta com muitos movimentos representativos, dentre os quais, a Confederação Nacional dos Trabalhadores em Educação (CNTE), a União Nacional dos Conselhos Municipais de Educação (UNCME), a União Nacional dos Estudantes (UNE), a União Brasileira dos Estudantes Secundaristas (UBES) e a Associação Nacional Pela Formação de Professores (ANFOPE). O âmbito que poderia ser compreendido como avanço no conjunto do PDE quanto à educação básica foi a instituição do IDEB, o "Provinha Brasill" e o Piso Salarial do Magistério. Os dois primeiros por considerarem a relação do rendimento do aluno com os fluxos de evasão, repetência e esforços para 
os aspectos qualitativos e o terceiro, como meta que prometia "melhorar" o investimento na dignidade do professor pelo reconhecimento de seu papel social.

Ora, se há a defesa de democratização da educação e sua proporcional expansão em todos os níveis, haveria que se buscar a instituição de fóruns representativos em que todas as vozes pudessem expressar a sua contribuição social e inferências que orientariam as conquistas sociais. Entretanto, o PDE se constituiria como instrumento fragmentário e fragmentado das correções que se desejava e, o pior, não havia precisão e previsão de investimentos específicos do PIB em educação frente aos desafios que se faziam naquele momento.

Havia o reconhecimento de que se pensar num percentual para a educação via PIB era necessário, mas nada que ultrapassasse a casa dos 5\% naquele momento. Não somente a boa vontade, como aponta Saviani (2009), seria suficiente para se alcançar a educação de qualidade que a sociedade brasileira necessitava, uma vez que os recursos financeiros significativos para dar condução ao PDE, distintos dos 3,5\% do PIB que até aquele momento era aplicado, não dariam conta de cobertura da educação como um todo. Se falava sobre a projeção de 5\% em 2007, o que Saviani destacava era que desde 1997 ele chamara a atenção para o percentual de $8 \%$ como necessário ${ }^{2}$.

E quanto à educação superior? O cenário de oportunizações, dir-se-á, não é o mesmo que em épocas passadas, uma vez que as políticas públicas para educação tem se preocupado na diminuição das desigualdades sociais e econômicas, inclusive para a educação superior, como por exemplo, com a instituição do REUNI, aumentando-se o número de vagas nas instituições federais e promovendo-se a inclusão social para pobres e grupos étnicos, a democratização do acesso ao ensino superior via iniciativa privada com recursos do PROUNI e FIES, a ampliação de vagas nos IFETs e o acompanhamento da qualidade da educação via SINAES?

Esse quadro não é uma mostra de que a educação no Brasil está de fato universalizada? De que todos têm a mesma possibilidade de conquistar por seu mérito a projeção profissional que quiser, bastando somente escolher o canal adequado para isso ? A educação inclusiva não está se dando por distintos instrumentos, como por exemplo a recente adoção de políticas de cotas para ingresso ao ensino superior?

Não pretendendo esgotar a discussão que se fará na próxima seção, vale destacar algumas contribuições de Dias Sobrinho (2012), quando observa que

2 Hoje, na luta pelos $10 \%$ do PIB para a educação, há inúmeras objeções, quanto a capacidade de investimentos na educação, uma delas é a do atual ministro da fazenda Guido Mantega que afirmou que "[...] 10\% do PIB para educação quebraria o país" (SANTOS, 2012). 
uma educação democrática e universalizada requer muito mais do que reconhecimento do direito ao direito, ou seja, reúne quantidade e qualidade como extensão material para todos. A ideia de povo como unidade requererá também a modificação das orientações dos discursos políticos para educação, ao ponto de ao invés de se falar em educação inclusiva, se vivencie a educação não excludente, ao invés de se destacar a porcentagem de vagas para determinada fração social, haja a oferta como direito e conquista para todos.Nesse caso, o Brasil está longe de uma educação universalizada no ensino superior e a dimensão da democratização do acesso é reduzida ao atendimento fragmentado de percentagens de grupos sociais nas universidades públicas, além de, em alguns casos, serem oferecidos cursos que poderiam ser considerados como niveladores de classe social e oferecidos em larga escala em instituições particulares (e subsidiados via PROUNI e FIES), destino certo dos candidatos expropriados de condições materiais e que a elite repudia como escolha para seus filhos.

Há que se pensar em investimentos para a educação, há que se elevar sim o percentual do PIB para se começar, entretanto, existem questões de fundo que precisam ser reelaboradas pela sociedade brasileira e que passam pelo questionamento e a vontade de superação do imperativo capitalista. Então não basta dizer que no Brasil "somente não estuda quem não quer", há que se construir uma dimensão de democracia em que o direito de educação de qualidade desde a infância seja alcançado pela totalidade, ao ponto de que haja dignificação para todos os cidadãos e com isso a própria sociedade seja dignificada. Mas este caminho não poderá ocorrer por concessão, antes é uma reivindicação política, um dos principais desafios para a maioria da população brasileira, uma vez que não será a elite que encampará qualquer mudança estrutural.

Se de fato o PDE, que tem previsão de alcance de suas metas até 2022, pretende articulado ao PNE (2011-2020) promover o sentido e a concretização de uma educação de qualidade para todos os brasileiros, não pode deixar à margem tais questões, pois são definidoras do direito à construção da cidadania e definidoras também do crescimento econômico. Nas palavras de Dias Sobrinho (2012, p. 17): "Uma sociedade que não consegue, ou não quer, estender os benefícios da escolarização de boa qualidade para todos, além de estar condenada ao empobrecimento crescente no sistema mundial de alta competitividade, é também uma sociedade perversa".

Acompanhamos estarrecidos que, todo o "empenho" por massificação da educação, quer Básica, quer do Ensino Superior, por meio de políticas públicas pontualizadas ou outros paliativos, não erradica as desigualdades sociais e nem tão pouco promove horizontalmente o direito de acesso, permanência, 
humanização e democratização de oportunidades, muito embora o discurso reforce o contrário e ainda quando de sua diminuição, poderia se dizer que é mais representativa do que substantiva.

A ambivalência de discursos nas políticas públicas de educação, apropriandose do ideário da solidariedade universal, defende que a civilização humana alcançou tamanho grau de reflexão sobre o futuro da humanidade, que não se justifica um quociente de poder desigual (LIMA, 2012). Por outro lado, o capital globalizado, que distante de favorecer quaisquer mudanças estruturais para a emancipação e libertação do sujeito social, universalizando sua condição de sujeito histórico, cunha artifícios para a ratificação de sua ideologia em nome da atenuação das tensões sociais, quer por meio de promoção de fundos de inversão para causas pontuais, quer pela indução de programas sociais condicionados aos empréstimos de organismos multilaterais aos Estados nacionais e dos acordos que, no caso brasileiro, são evidentes de longa data.

A partir de tais considerações, a seguir se destacará o âmbito da expansão dos institutos federais pelo Brasil via PDE, a sua capacidade de indução da redução das desigualdades inter-regionais na relação oferta de vagas e demandas e a sua projeção como instrumento de promoção para a democratização do acesso à educação profissional e tecnológica.

\section{O PROCESSO DE INTEGRAÇÃO DE INSTITUIÇÕES FEDERAIS DE EDUCAÇÃO TECNOLÓGICA E A REDUÇÃO DAS DESIGUALDADES INTER-REGIONAIS}

$\mathrm{O}$ aumento da capacidade do setor produtivo brasileiro previsto no PPA (2000-2003) por meio da criação dos fundos setoriais em número de 14, a reorganização do $\mathrm{MCT}$ por conta da reestruturação produtiva mundial e as demandas das políticas educacionais para a realidade do mundo globalizado exigiriam do governo posterior (Lula) encaminhamentos que refletissem um atendimento mais amplo quanto à oferta da educação brasileira como um todo. Para a finalidade dessa seção destacamos a educação profissional e tecnológica.

No PPA (2004-2007) é de se notar que a ênfase central da agenda do governo se assenta sobre a relação do aumento na produtividade e distribuição de renda ${ }^{3}$.

3 Exemplo dessa afirmação está no tópico 8 do capítulo I desse documento (BRASIL, 2004, p. 8), que denuncia "A ausência de um projeto de desenvolvimento e de claras políticas setoriais (industrial, de comércio exterior, agrícola, educacional, de ciência e tecnologia etc.) resultou na falta de foco dos Planos Plurianuais precedentes [...]", mais adiante continua no mesmo tópico: "Dadas as características atuais do Estado, da sociedade e do sistema produtivo brasileiros, a atividade de planejamento deve ser compreendida como coordenação e articulação dos interesses públicos e privados no sentido de minorar a pobreza da população, minimizar as desigualdades sociais e regionais, redistribuir renda, reduzir o desemprego, 
A princípio o leitor do documento poderia pensar que a dimensão democrática alcançaria enfim a melhor oportunidade para a sua consolidação. Entretanto, no prosseguimento da leitura se expressa o comprometimento de se garantir o pano de fundo necessário para a tipologia de sociedade de que o Brasil fora historicamente signatário e não diferia em finalidade do governo anterior, o que sim se diferirá será o alcance de algumas políticas públicas, entretanto, sem romper com a estrutura social de oferta educacional de classes.

Sem necessariamente discursar sobre os distintos levantamentos estatísticos sobre a educação profissional e tecnológica, mas dispondo de uma breve observação sobre o quadro que se instalara no Brasil até 2007, momento em que o PDE - via Decreto 6095/2007 estabelecera metas especificas sobre essa modalidade - destaca-se que o IBGE (2012) divulgou as seguintes informações:

As instituições de ensino vinculadas ao Sistema " $\mathrm{S}$ "2 atendiam 20,6\% (7,4 milhões) das pessoas que frequentavam ou frequentaram anteriormente algum curso de educação profissional - percentual inferior ao das instituições particulares de ensino ( $53,1 \%$, ou 18,9 milhões) e ao de instituições públicas de ensino $(22,4 \%$, ou 8,0 milhões de pessoas).Nas regiões Sul e Centro-Oeste, as instituições do sistema "S" apresentaram percentuais de frequência (24,0\% e 24,3\%, respectivamente) superiores ao das instituições de ensino público $(21,7 \%$ e $22,9 \%$ respectivamente). Apenas nas regiões Nordeste $(49,7 \%)$ e Sul $(49,2 \%)$, a rede de ensino particular não atendeu mais que a metade das pessoas que frequentavam ou frequentaram a educação profissional.

É interessante destacar que até então predominavam as instituições particulares no atendimento à qualificação profissional ou oferta de cursos técnicos ou de graduação, considerando a população de 10 anos a mais. A tabela a seguir evidencia a descrição efetuada.

Deve-se observar que no âmbito da educação profissional e tecnológica são considerados três diferentes cursos: a) de formação inicial e continuada ou qualificação profissional; b) de educação profissional técnica de nível médio e c) de educação profissional tecnológica de graduação e pós-graduação; conforme a LDBEN 9394/96. Neste caso (Tabela 1) houve um percentual (em milhões) predominante da iniciativa privada sobre a oferta das instituições de ensino superior, principalmente no que se refere à cursos de qualificação profissional com a exigência mínima do ensino fundamental e em nível técnico e tecnológico havia um descompasso na oferta em nível de instituições públicas, ou seja, a

superar a escassez de financiamento, reduzir incertezas e elevar o investimento público e privado". 
expansão e a democratização do acesso deveriam ser revistas, inclusive com a desconcentração das instituições em regiões tradicionalmente já desenvolvidas com vistas à redução das desigualdades inter-regionais.

No Plano de Desenvolvimento da Educação, por meio do Decreto 6095 de 24/04/2007 foram estabelecidas diretrizes para o processo de integração de instituições federais de educação tecnológica, para fins de constituição dos Institutos Federais de Educação, Ciência e Tecnologia - IFETs, no âmbito da Rede Federal de Educação Tecnológica. Nesse decreto estava expresso o reconhecimento da insuficiência da oferta de educação profissional e tecnológica, daí o destaque no artigo 1, para a reorganização e a convocação para a atuação integrada nas distintas regiões da federação, que deveriam reunir esforços (artigo 3) para a agregação voluntária de Centros Federais de Educação Tecnológica - CEFETs, Escolas Técnicas Federais - ETF, Escolas Agrotécnicas Federais - EAF e Escolas Técnicas vinculadas às Universidades Federais, localizados em um mesmo Estado.

A arquitetura dessa política educacional em si apresentava pontos positivos se pensarmos na explícita declaração da oferta de formação profissional e tecnológica em todos os níveis e modalidades (básica, técnica, tecnológica - essa última com status dos cursos superiores oferecidos no Brasil), compreendendo

Tabela 1 - Distribuição percentual das pessoas com 10 anos ou mais de idade que frequentavam ou frequentaram anteriormente curso de educação profissional, por natureza da instituição de realização do curso, segundo as Grande Regiões - 2007

\begin{tabular}{|c|c|c|c|c|c|}
\hline \multirow[b]{3}{*}{ Grandes Regiões } & \multicolumn{5}{|c|}{$\begin{array}{l}\text { Distribuição percentual das pessoas de } 10 \text { anos } \\
\text { ou mais que frequentavam ou frequentaram } \\
\text { anteriormente curso de educação profissional (\%) }\end{array}$} \\
\hline & \multirow[t]{2}{*}{ Total } & \multicolumn{4}{|c|}{ Natureza da instituição de realização do curso } \\
\hline & & $\begin{array}{l}\text { Instituição } \\
\text { de ensino } \\
\text { vinculada ao } \\
\text { sistema "S" }\end{array}$ & $\begin{array}{l}\text { Instituição } \\
\text { de ensino } \\
\text { publico }\end{array}$ & $\begin{array}{l}\text { Instituição } \\
\text { de ensino } \\
\text { particular }\end{array}$ & Outra \\
\hline Brasil & 100,0 & 20,6 & 22,4 & 53,1 & 3,9 \\
\hline Norte & 100,0 & 22,5 & 22,8 & 21,1 & 3,6 \\
\hline Nordeste & 100,0 & 18,2 & 27,9 & 49,7 & 4,2 \\
\hline Sudeste & 100,0 & 19,6 & 20,2 & 56,8 & 3,5 \\
\hline Sul & 100,0 & 24,0 & 21,7 & 49,2 & 5,2 \\
\hline Centro-Oeste & 100,0 & 24,3 & 22,9 & 50,4 & 2,5 \\
\hline
\end{tabular}

Fonte: IBGE. Diretoria de Pesquisas. Coordenação de Trabalho e rendimento. Pesquisa Nacional por Amostra de Domicílios, 2007. 
cursos de formação inicial e continuada de trabalhadores em geral, do PROEJA, além de mestrados, bacharelados, aperfeiçoamentos e licenciaturas, pesquisa e extensão. A meta (Cf. Art. 3, Inciso I) era a de formar e qualificar profissionais para os diversos setores da economia, em estreita articulação com os setores produtivos e a sociedade.

A planificação do PDE ganharia robustez com a Lei 11892 de 29/12/2008 com a instituição da Rede Federal de Educação Profissional, Científica e Tecnológica e criação dos Institutos Federais de Educação, Ciência e Tecnologia. Isso significava que como autarquias, os institutos poderiam expandir a sua oferta, bem como o número de unidades conforme as demandas regionais identificadas.

Sabermos a necessidade de se pensar a educação como um todo quer num percurso formativo via universidade e cursos de educação superior tradicionais, quer em nível técnico e tecnológico não é algo novo; se sabe e se faz muito bem essa discussão em âmbito nacional, o que não se deve num país democrático é condicionar a oferta de cursos à indução de uma amostragem da classe trabalhadora com o discurso de atendimento em suficiência às solicitações sociais, a isto Frigotto (2007) chamou de políticas focais. Com isso se mantém a desigualdade como produto e condição do projeto dominante da sociedade brasileira e as mudanças estruturais necessárias são colocadas à margem de quaisquer discussões e a culpabilidade da não inserção no quadro das oportunidades sociais recai sobre a responsabilização do jovem que não buscou o seu lugar ao sol.

Até que ponto tal justificativa pode ter sustentação se, por exemplo, os dados de 2007, mostravam que apenas $46 \%$ dos jovens tinham acesso ao ensino médio? Se mesmo com o aumento do número de unidades dos institutos federais pós-PDE (que chegou à evolução de 214 unidades no governo Lula), existe uma filtragem para o ingresso de tais oportunidades? Ver evolução de matrículas no gráfico a seguir.

Não há dúvidas de que houve aumento no número de matrículas para a educação profissional e tecnológica condicionadas pelos arranjos do PDE, mas se pergunta até que ponto pode-se afirmar que esse quadro representa um direcionamento para a democratização e não indução somente de um percentual representativo como colocado anteriormente? A expansão tem atingido de fato a sua finalidade quanto à sua projeção inter-regional?

Como o PDE ainda está em curso não se pode afirmar ou negar a última questão, no entanto, se tomada a realidade atual, se pode dizer que ainda falta muito para a oferta de cursos via implantação dos IFETs se tornar uma 


\section{EXPANSÃO DA REDE FEDERAL DE \\ EDUCAÇAO PROFISSIONAL E TECNOLOGICA}

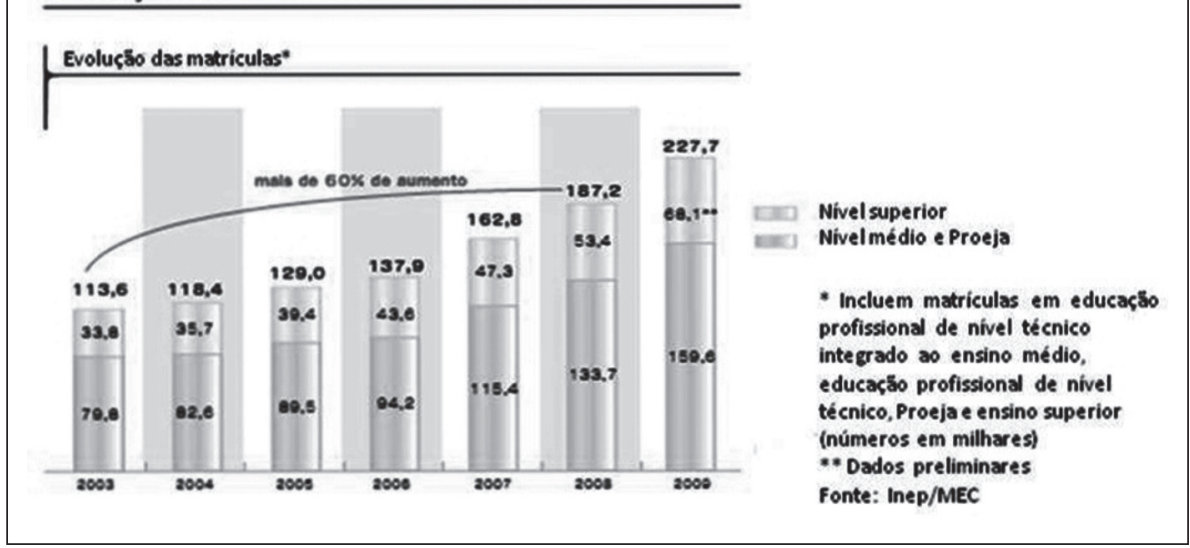

Fonte: INEP/MEC. Sinopse das Ações do Ministério da Educação, Brasília, p. 74, 2010. Disponível em: $<$ http://gestao2010.mec.gov.br/indicadores/chart_49.php>. Acesso em: 08 jul. 2012.

distribuição equilibrada, principalmente nas regiões centro-oeste, nordeste e norte. Outro ponto importante é que mesmo com uma maior concentração de institutos nas grandes regiões, como a sudeste e mais recortadamente o estado de São Paulo, não se tem conseguido atingir um patamar expressivo de jovens na garantia de vagas nesses cursos - ou pela insuficiência de vagas ou pelas condições de renda e a conformação à subempregos, variáveis que não que se pode colocar à margem quanto à compreensão do quadro.

Ora, então se tem uma questão mais ampla para se pensar - a educação para todos desde as etapas iniciais com suficiência de condições para que realmente não haja somente o reconhecimento da igualdade de direitos, mas a sua facticidade, caso contrário perdurarão as políticas focais e esperar-se-á mais um século para que as mudanças necessárias aconteçam.

Em pesquisa desenvolvida pelo Comitê Técnico do Observatório da Equidade (WEGRZYNOVSKI, 2008) formado por pesquisadores do Instituto de Pesquisa Econômica Aplicada (IPEA), do Instituto Brasileiro de Geografia e Estatística (IBGE), do Departamento Intersindical de Estatística e Estudos Socioeconômicos (Dieese), da Secretaria do Conselho de Desenvolvimento Econômico e Social, além dos conselheiros e especialistas em educação, é afirmado que os pobres vão menos à escola, falta educação profissional e tecnológica para os jovens, somente metade dos alunos brasileiros conclui o ensino 
fundamental e $67 \%$ finalizam o ensino médio. O estudo revela que há que se desenvolver sim políticas de expansão da oferta de educação para a educação profissional e tecnológica, mas sem se esquivar do necessário, a trajetória da vida escolar do estudante, os investimentos para que a educação possa ser de fato igualitária, a garantia de condições materiais da existência da população, não como massa, mas como exercício de cidadania.

Ora, hoje (2012) se tem menos de um milhão de jovens na educação profissional e tecnológica no Brasil (recortando-se os cursos técnicos e tecnológicos) e maior demanda para alunos dos cursos superiores, dos quais historicamente a elite ocupa as vagas dos cursos que conferem maior status econômico e social (medicina, direito e engenharias) na universidade pública e deste quadro indaga-se se todos os jovens são atendidos por instituições públicas? Existe espaço para todos nas distintas ofertas e modalidade de cursos?

Na sociedade contemporânea a valorização do trabalho como instrumento de emancipação do homem está aquém do reconhecimento da equidade. Isso se dá pelas distorções provocadas por interesses de grupo, pelo monopólio de um saber elitizado que, embora sujeito a algumas críticas e desafios tem se mantido perene com o passar dos tempos. E certamente as políticas públicas ainda não avançaram de forma suficiente para garantir a correção de tal quadro, pois predominam os interesses para a manutenção do mesmo.

No Brasil quanto à sua natureza as políticas públicas podem ser caracterizadas como conjunturais ou emergenciais (objetivam amainar uma situação temporária, imediata), quanto a abrangência dos possíveis benefícios são segmentais (voltadas para um segmento da população, caracterizado por um fator determinado (idade, condição física, gênero etc.) e fragmentadas (destinadas a grupos sociais dentro de cada segmento), quanto aos impactos que podem causar aos beneficiários, ou ao seu papel nas relações sociais são mais distributivas (visam distribuir benefícios individuais; costumam ser instrumentalizadas pelo clientelismo do que redistributivas (visam redistribuir recursos entre os grupos sociais: buscando certa equidade, retiram recursos de um grupo para beneficiar outros, o que provoca conflitos) e ainda são regulatórias, isto é, visam definir regras e procedimentos que regulem comportamento dos atores para atender interesses gerais da sociedade; não visariam benefícios imediatos para qualquer grupo (TEIXEIRA, 2011).

Para que as políticas públicas de educação pudessem de fato corresponder as solicitações por universalização e democratização deveriam ser, quanto a sua natureza ou grau de intervenção, estruturais, possibilitando condições igualitárias das oportunidades sociais disponíveis para todos os estudantes, ao 
mesmo tempo em que universais e regulatórias, garantindo-se a educação como prioridade, portanto, não excludente em sua finalidade. Ora, na organização social que tem o capital como sustentação isso dificilmente ocorrerá, daí ser o mais comum manter-se a estrutura sistêmica e favorecer a inclusão como plataforma de atendimento à percentuais representativos.

\section{O REUNI/ PROUNI/ FIES E AS SOLICITAÇÕES DA REALIDADE BRASILEIRA: POR UMA EDUCAÇÃO SUPERIOR UNIVERSALIZADA}

A expansão e frequência ao ensino superior na última década, conforme a PNAD, deveu-se a três iniciativas: a) o REUNI com o aumento das vagas em universidades federais, b) o aprimoramento e ampliação do Programa de Financiamento Estudantil (Fies) e c) a criação do Programa Universidade para Todos (PROUNI) para fazer frente ao não alcance da meta estipulada pelo PNE (2001-2010) de que pelo menos 30\% de jovens entre 18 e 24 estariam cursando o ensino superior no Brasil. De acordo com os dados do IBGE (2010), considerando o universo de 23,03 milhões de jovens nesta faixa etária, somente 3,36 milhões estavam matriculados na educação superior, portanto, muito aquém da taxa líquida e bruta pretendidas ${ }^{4}$.

O REUNI, como uma das manifestações do PDE, foi estabelecido por meio do Decreto $n^{\circ}$. 6096, de 24 de abril de 2007, tendo como finalidade a de criar condições para a ampliação do acesso e permanência na educação superior em nível de graduação, aproveitando a estrutura física e os recursos humanos existentes nas universidades federais (BRASIL, 2007). Às universidades que fizessem a adesão ${ }^{5}$ ao REUNI, seriam oferecidos recursos para a ampliação de estruturas físicas e tecnológicas e contratação de docentes e técnicos. Como contrapartida as universidades deveriam apresentar um percentual de $90 \%$ de conclusões nos cursos de graduação e a relação de 18 alunos ${ }^{6}$ por professor. Com isso todas as universidades federais brasileiras aderiram ao REUNI.

4 A taxa líquida corresponde ao número total de matrículas para determinada faixa etária $(14,6 \%$ para os jovens entre 18 e 24 anos de idade) e a taxa bruta corresponde ao número total de pessoas matriculadas na educação superior independente da idade (25,8\% da meta do PNE 2001-2010).

5 Cada instituição federal que fizesse adesão ao REUNI deveria elaborar um Plano Institucional, conforme as diretrizes estabelecidas, em que seriam explicitadas as etapas a serem desenvolvidas para o alcance das metas do programa.

6 A partir de dados da OCDE, Schwartzman (2012) esclarece que a média mundial da relação estudanteprofessor é de 14,9. O Japão 10,1; a Alemanha 11,9; a Noruega 9,2; na Suécia 8,8; na Rússia 12,7; os EUA 15,3. Em 2010, segundo o Censo da Educação Superior e a CAPES, o Brasil atinge uma relação de 17,9, embora atingindo o percentual previsto, ainda está aquém do que se espera para a oferta de uma educação de qualidade. 
Como um dos resultados dessa iniciativa houve um crescimento de $20,4 \%$ de matrículas nos cursos de graduação presencial, entretanto, observando-se que ao custo de salas superlotadas e alocação de recursos insuficientes para a continuidade de expansão, além do que, a contenção ao acesso à educação superior, principalmente a pública, ainda permanece no Brasil, como processo que tem início muito antes do vestibular.

Conforme Corbucci (apud GARSCHAGEN, 2007, p. 01) isso se dá, “[...] a começar pelo fato de que quase metade dos estudantes que iniciam o ensino fundamental não consegue concluí-lo". Além do que, enormes percentagens daqueles que concluem o ensino médio “[...] não dispõem de condições mínimas para disputar, com os que estudaram em condições mais vantajosas, uma das vagas ofertadas pelas instituições de ensino públicas e tampouco dispõem de recursos para arcar com os custos do ensino privado." Mesmo que, por outras vias, mediante políticas de ações afirmativas, os dados não se alteram e não dão conta de atendimento às demandas de jovens que necessitariam de educação de qualidade em instituições públicas.

Como alternativa ao atendimento das demandas, o PROUNI, criado em 2004 e institucionalizado em 2005, tem a finalidade de conceder bolsas parciais ou integrais a estudantes de baixa renda para o ingresso a cursos presenciais de educação superior em instituições privadas, em contrapartida essas instituições recebem isenções fiscais do governo federal. Dito de outra forma, seria uma maneira de destinação de dinheiro público ao ensino privado, o que segundo Sguissardi (2006) isso pode ser caracterizado como um desvio de propósito da oferta de ensino de qualidade para todos, pois as instituições privadas, embora priorizem as atividades de ensino, são avaliadas como de baixa qualidade, enquanto que as públicas em tese seriam de melhor qualidade.

Uma outra forma ou maneira alternativa para o "atendimento" a um percentual representativo de pessoas de baixa renda quanto ao acesso à educação superior é o FIES, cujo objetivo é a disponibilização de financiamento para estudantes de baixa renda matriculados em instituições privadas. Instituído em 1999 e orientado pelo FNDE (Fundo Nacional de Desenvolvimento da Educação), o FIES, por meio da Lei n ${ }^{\circ} .11 .552$ de 19/11/2007 alterou os limites de financiamento, bem como o período de carência e diminuição de juros para os estudantes. Assim, PROUNI e FIES tem sido instrumentos que tem contribuído para a expansão da educação superior privada, que representa hoje no Brasil o atendimento de quase $75 \%$ das vagas.

Todo esse quadro de desenvolvimento em relação à educação superior poderia apresentar o quanto já avançamos, entretanto, recente pesquisa coordenada 
por Andrade e colaboradores (2012) da Unicamp, a partir de dados da PNAD e do IBGE, afirmam que mais de $80 \%$ de jovens entre 18 e 24 anos ainda não têm acesso ao ensino superior, obstáculo que precisa ser trabalhado e vencido em meio às demandas de cidadãos com cor autodeclarada e pobres dentre outros. A tabela a seguir propicia uma visão mais precisa da informação apresentada:

\section{Tabela 2 - Taxa da população com idade entre 18 e 24 anos, segundo o nível de escolaridade. Brasil - 2009}

\begin{tabular}{lr} 
Situação escolar & $\%$ \\
\hline Não concluiu o ensino fundamental & $21 \%$ \\
\hline Concluiu apenas o ensino fundamental & $27 \%$ \\
\hline Concluiu o ensino médio & $33 \%$ \\
\hline Tiveram acesso ao superior & $19 \%$ \\
\hline TOTAL & $\mathbf{1 0 0 \%}$
\end{tabular}

Fonte: Elaboração dos autores a partir de dados das PNADs/IBGE, 2009. Disponível em: <http://www. ibge.gov.br/home/estatistica/populacao/trabalhoerendimento/pnad2009/>. Acesso em: 03 out. 2012.

Outro ponto de destaque, considerando o universo de $19 \%$ de ingressantes no ensino superior, é o de que, embora esteja desenhado que a regulação da qualidade da educação superior no Brasil se faria mediante o Sistema Nacional de Avaliação da Educação Superior (SINAES) ${ }^{7}$, cuidando para que os cursos de baixa qualidade não fossem oferecidos, dados recentes revelam que $38 \%$ dos matriculados em educação superior não dominam habilidades básicas de leitura e escrita, conforme o Indicador de Alfabetismo Funcional (INAF), divulgado pelo Instituto Paulo Montenegro (IPM) e pela ONG Ação Educativa. Para Azevedo (2012) este indicador reflete o expressivo crescimento de universidades de baixa qualidade e como um todo urge a necessidade de se pensar e estruturar uma educação superior com qualidade propriamente dita.

Isso não se fará somente com sistemas ou programas de aferição de resultados, nem com políticas focais como resolutórias da problemática sobre educação superior no Brasil, mas na organização, estrutura e funcionamento da oferta, apesar da estrutura social do capital, para que se ao menos tente alguma democratização do acesso, permanência e conclusão de cursos superiores pela maior parte da população e isso é um trabalho de base, pois como visto na pesquisa de Andrade e colaboradores (2012),

7 O SINAES foi instituído pela Lei $\mathrm{n}^{\circ} 10.861$ de 14/04/2004, cuja finalidade centrava-se, dentre outros pontos na "[...] melhoria da qualidade da educação superior [...]" (BRASIL, 2004). 
são $80 \%$ de jovens entre 18 e 24 anos que estão à margem do processo da educação superior por defasagens ao longo de sua formação escolar. A correção de tal fluxo tem que passar ao menos por uma equiparação entre os investimentos do que se aplica para formar um aluno em educação superior em relação ao aluno da educação básica, pois é esse que depois buscará o acesso ao ensino superior.

\section{CONSIDERAÇÕES FINAIS}

A universidade tem sido objeto de distintas discussões, apresentando posicionamentos diversos, incluindo aqueles que insistem que o processo de expropriação histórica é mais cultural do que socioeconômico, sem se ater na totalidade da relação capital-trabalho que efetivamente promove a manutenção da não universalização, mesmo em face de um discurso que afirme o contrário. Qual o caminho? Recuperar o sentido entre direito, democracia, universalização e humanização como objetos inalienáveis da história e manifestações humanas que não se dará de forma gratuita ou naturalmente, mas por meio da manifestação do homem na história e com a história.

Nesse olhar, enquanto há enfrentamentos de fervorosos grupos sociais organizados na lógica da defesa ou não desse arranjo, não há porque alterar qualquer disposição de estrutura social que conduza à democratização da universidade no Brasil. Observa-se que o exercício da educação superior somente alcançará uma dimensão humanizadora, democrática e universal quando não se limitar a medidas paliativas, que se preocupam muito mais em esvaziar as vozes do que promover uma transformação social verdadeiramente qualitativa. Mas é sim por meio da problematização de tais medidas que outros encaminhamentos poderão ser considerados.

A trajetória de uma universidade no âmbito da justiça social rompe com tal lógica, conferindo aos homens indistintamente, tornarem-se homens, pela superação das práticas dissimuladoras na centralidade capital-trabalho; pela ação comunicacional entre direito e democracia sem particularismos; pela leitura e encaminhamentos das problemáticas da educação e sociedade por meio da dialética do concreto e pelo esclarecimento que emancipa sem distorção de seu campo real e conceitual. Não pode haver silenciamento em detrimento de qualquer mudança substancial que transforme o acesso à universidade em seu sentido mais profundo de libertação, humanização e universalização, articulando a mobilização pela superação da divisão social do trabalho e de classes. 


\section{REFERÊNCIAS}

ANDRADE, C. Y. de et al. Acesso ao ensino superior no Brasil: equidade e desigualdade social. Disponível em: $<\mathrm{http} / / \mathrm{www}$.revistaensinosuperior. gr.unicamp.br/noticia. php?id=135>. Acesso em: 03 out. 2012.

AZEVEDO, R. A universidade na era apedeuta: no ensino superior, 38\% dos alunos não sabem ler e escrever plenamente. Veja On-Line. Disponível em: <http:// veja.abril.com.br/blog/reinaldo/geral/a-universidade-da-eraapedeuta-no-ensino-superior-38-dos-alunos-nao-sabem-ler-e-escreverplenamente/>. Acesso em: 02 ago. 2012.

BRASIL. Lei $\mathbf{n}^{\circ} \mathbf{1 0 8 6 1}$, de 14 de abril de 2004. Institui o Sistema Nacional de Avaliação da Educação Superior - SINAES e dá outras providências. Portal do MEC. Brasília: Senado Federal, 2004. Disponível em: <http:// portal.mec.gov.br/ arquivos/pdf/ leisinaes.pdf>. Acesso em: 02 ago. 2012. BRASIL. Ministério do Planejamento, Orçamento e Gestão. Plano Plurianual (2004-2007): orientação estratégica de governo um país para todos: crescimento sustentável, emprego e inclusão social. Brasília, 2004. BRASIL. Razões e princípios do Plano de Desenvolvimento da Educação. Disponível em: <http://portal.mec.gov.br/arquivos/livro/livro. pdf $>$. Acesso em: 03 jul. 2012.

BRASIL. Decreto ${ }^{\circ}$ 6.096, de 24 de abril de 2007. Institui o Programa de Apoio a Planos de Reestruturação e Expansão das Universidades Federais - REUNI. Brasília: Casa Civil. Disponível em: $<$ http://www.planalto.gov. br/ccivil_03/_ato2007-2010/2007/decreto/d6096.htm>. Acesso em: 02 ago. 2012.

DECLARACIÓN MUNDIAL SOBRE LA EDUCACIÓN SUPERIOR EN EL SIGLO XXI: VISIÓN Y ACCIÓN. Avaliação, Cipedes, Campinas, v. 1, n. 3, dez. 1998.

DIAS SOBRINHO, J. Educação superior: bem público, equidade e democratização. In: SEMINÁRIO TENDÊNCIAS DA EDUCAÇÃO SUPERIOR NO BRASIL, 1. 2012, Sorocaba, SP. Sorocaba: Uniso; Ufscar, 2012. (Seminário).

FRIGOTTO, G. A relação da educação profissional e tecnológica com a universalização da educação básica. Educ. Soc., Campinas, v. 28, n. 100 Especial, p. 1129-1152, out. 2007. 
GARSCHAGEN, S. Em busca do ensino ideal: há avanços inequívocos em relação à década passada e muitos problemas a enfrentar. Desafios do Desenvolvimento, Brasília, n. 37, nov. 2007.

IBGE. IBGE divulga perfil da educação e alfabetização de jovens e adultos e da educação profissional no país. 2012. Disponível em: $<$ http:// www.ibge.gov.br/home/presidencia/ noticias/noticia_visualiza.php?id_ noticia $=1375 \&$ id_pagina $=1>$. Acesso em 10 jul. 2012.

LIMA, P. G. Políticas científicas e tecnológicas: países avançados, América Latina e Brasil. Dourados: Editora da UFGD, 2009.

LIMA, P.G. Universidade brasileira: por uma dimensão universal, humana e democrática. São Paulo: Annablume, 2012.

RAMOS, E. De que participação estamos falando? In: GRACIANO, M. (Coord.). O plano de desenvolvimento da educação. São Paulo: Ação Educativa, 2007.

SANTOS, D. Mantega: 10\% para a educação quebraria o país.

Disponível em: $<$ http://noticias.terra.com.br/educacao/noticias/0,,OI587608 4EI8266,00Mantega + do + PIB + para + a + educacao + quebraria + o + Pais $>$.html. Acesso em: 07 jul. 2012.

SAVIANI, D. PDE plano de desenvolvimento da educação: análise crítica da política do MEC. São Paulo: Autores Associados, 2009.

SCHWARTZMAN, J. A experiência do Reuni nas universidades federais: sua concepção e primeiros resultados. In: SEMINÁRIO SOBRE EDUCAÇÃO SUPERIOR/CENTRO DE ESTUDOS AVANÇADOS DA UNICAMP, Campinas, 18 a 21 de julho de 2012.

SGUISSARDI, V. Reforma universitária no Brasil - 1995-2006: precária trajetória e incerto futuro. Educ. Soc., v. 27, n. 96, out. 2006.

TEIXEIRA, E. C. O papel das políticas públicas no desenvolvimento local e na transformação da realidade. Disponível em: $<$ http://www.fit.br/ home/link/texto/ politicas publicas.pdf $>$. Acesso em: 20 jul.2011.

WEGRZYNOVSKI, R. Ainda vítima das iniquidades : observatório da equidade faz "radiografia" da Educação com resultados preocupantes.

Desafios do Desenvolvimento, Brasília, n. 40, jul. 2008. 
